\title{
Climate-driven synchrony across tree, bivalve, and rockfish growth-increment chronologies of the northeast Pacific
}

\author{
Bryan A. Black* \\ Hatfield Marine Science Center, Oregon State University, 2030 SE Marine Science Dr., Newport, Oregon 97365, USA
}

\begin{abstract}
Interrelationships are analyzed among growth-increment chronologies of yelloweye rockfish Sebastes ruberrimus, splitnose rockfish Sebastes diploproa, and the bivalve species Pacific geoduck Panopea abrupta in the northeast Pacific. The chronologies are annually resolved, multidecadal in length, and range in location from central California through northern British Columbia. In a principal components analysis, the first component explained $52 \%$ of the variance in the dataset and separated chronologies from the northern half of the study area from those in the southern half. The northern chronologies significantly and positively correlate with seasonally averaged records of the Multivariate ENSO Index (MEI) and the Pacific Decadal Oscillation (PDO), while the southern chronologies negatively correlate with the same variables, especially during the winter and spring. Such an inverse growth regime is consistent with primary and secondary productivity patterns in the northeast Pacific. The second principal component accounted for $23 \%$ of the variance in the dataset and captured a growth pattern associated with climatic variability in the spring and summer months. Both principal components derived from the marine chronologies relate to tree-ring chronologies in western North America, due to shared sensitivities to climatic variability. Interrelationships among these chronologies underscore the synchronous and pervasive impacts of climate on very diverse taxa and ecosystems in western North America.
\end{abstract}

KEY WORDS: Pacific rockfish $\cdot$ Pacific geoduck $\cdot$ Dendrochronology $\cdot$ Sclerochronology $\cdot$ Pacific Northwest · Climate Resale or republication not permitted without written consent of the publisher

\section{INTRODUCTION}

In forested ecosystems tree ring data have been widely used to reconstruct various aspects of climate, disturbance, and community dynamics such as temperature, precipitation, fire, windstorms, insect outbreaks, successional trends, and population age structure (Fritts 1976, Swetnam \& Betancourt 1990, Speer et al. 2001). Temporal and spatial scales captured by these reconstructions range from interannual to intercentennial and from forest stands to continents (Cook et al. 1999, Swetnam et al. 1999). Indeed, the extensive network of high-quality chronologies that now exists is one of the most important data sources for quantifying global patterns of climate variability and change
(Mann et al. 1998, Esper et al. 2002). Similarly, tree rings provide valuable baseline data for assessing landscape-level impacts of human land uses and altered disturbance regimes (Cissel et al. 1999, Taylor \& Skinner 2003). From an autecological perspective, dendrochronological analyses can also address such issues as species' tolerance to competition, climate sensitivity, growth rates, and longevity (Orwig \& Abrams 1994, Cook et al. 2001, Black et al. 2008b).

Beyond trees, a wide array of long-lived marine species including bony and cartilaginous fish, bivalves, and hermatypic and deep-sea corals also form annual growth increments, which occur in calcified or hardened structured such as otoliths, vertebrae, or shells (Campana 2001). Increments in these organisms arise 
due to seasonal variation in growth rates and can be used to investigate issues in marine taxa and ecosystems analogous to those addressed by tree-ring data in terrestrial settings. To date, most studies involve hermatypic corals or bivalves and rely on chemical or isotopic signatures such as ${ }^{18} \mathrm{O}$ or $\mathrm{Sr} / \mathrm{Ca}$ ratios as proxies of ocean temperature and circulation (Evans et al. 2002, Schone et al. 2004, Goodkin et al. 2005). However, growth-increment widths also strongly relate to various indices of ocean variability and provide a means for developing environmentally sensitive marine chronologies via more traditional dendrochronology techniques (Strom et al. 2004).

An important and relatively recent advance is the application of the dendrochronology method of crossdating to ensure that the correct calendar year is assigned to each growth increment in the dataset (Strom 2003, Black et al. 2005, Helama et al. 2006). Universally applied in tree-ring studies, cross-dating is the process of matching among all specimens in a sample set the synchronous growth patterns induced by climate. If an increment has been missed or falsely added, the synchronous growth pattern will be offset by a year relative to that in the other samples, and the point where the offset begins indicates the location of the error. Without cross-dating, errors can accumulate and diminish accuracy, especially in early portions of a chronology. For example, the error rate in corals is estimated to be approximately 1 to 2 yr per century, an amount that would not substantially affect estimates of long-term environmental variability, but may 'smear' the high frequency year-to-year signal (Hendy et al. 2003). Among the existing examples in bivalves, corals, and rockfish, crossdated chronologies are annually resolved and of a quality comparable to that of tree-ring chronologies, facilitating direct comparisons with instrumental records or other high-resolution proxies.

Despite growing interest in developing chronologies from marine organisms, this potential data source remains greatly underutilized. The diversity of species, ecosystems, and geographic locations for which chronologies exist could be substantially expanded, as could the range of topics addressed using these unique time series. This is particularly true for ecological issues, such as the interrelationships across diverse species, ecosystems, and spatial scales as well as the physical and biological environmental variables that most limit growth. In the present study, these issues were explored using cross-dated chronologies derived from growth-increment widths of 2 bottom-dwelling Pacific rockfish species, yelloweye rockfish Sebastes ruberrimus, and splitnose rockfish Sebastes diploproa, as well as a nearshore bivalve species, Pacific geoduck Panopea abrupta. Chronologies span central Califor- nia through northern British Columbia and represent various trophic levels, water depths, life histories, and productivity regimes in the northeast Pacific. More specifically, objectives were to examine interrelationships in growth patterns within and among species across a range of spatial scales and compare chronologies with instrumental climatic records to identify the environmental variables most closely associated with growth. Tree-ring chronologies located throughout the Pacific Northwest and Alaska were then included to explore similarities in growth patterns across marine and terrestrial ecosystems.

\section{MATERIALS AND METHODS}

Sample preparation and measurement. A total of 3 chronologies were developed for Pacific rockfish: one for splitnose rockfish (Black et al. 2005), one for yelloweye rockfish in northern California and one for yelloweye rockfish near Triangle Island, just north of Vancouver Island, British Columbia $\left(50^{\circ} 50^{\prime} \mathrm{N}\right.$, $128^{\circ} 40^{\prime} \mathrm{W}$ ) (Fig. 1). Splitnose rockfish were collected between $\sim 36^{\circ}$ and $40^{\circ} \mathrm{N}$ during surveys conducted by the Northwest and Alaska Fisheries Center, National Marine Fisheries Service, NOAA, in 1980, 1989, and 1995 (Black et al. 2005). California yelloweye rockfish were obtained by commercial and sport fishing vessels from $\sim 36^{\circ}$ to $40^{\circ} \mathrm{N}$ between 1977 and 2004, while the Canadian Department of Fisheries and Oceans collected all Triangle Island yelloweye samples during surveys in May 2003 over an area less than $200 \mathrm{~km}^{2}$. Otoliths were removed, dried, and then thin-sectioned, mounted to slides, and polished using standard techniques (Boehlert et al. 1989, Black et al. 2005, 2008a). Splitnose rockfish most commonly occur near the ocean floor between 215 and $350 \mathrm{~m}$, feeding primarily on krill, copepods, shrimps, and amphipods. Yelloweye rockfish most commonly occur near the ocean floor between 91 and $180 \mathrm{~m}$, feeding primarily on juvenile rockfish, herring, sandlance, and flatfishes as well as shrimps and crabs (Love et al. 2002).

Pacific geoduck chronologies were developed at

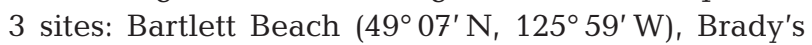
Beach $\left(48^{\circ} 48^{\prime} \mathrm{N}, 125^{\circ} 17^{\prime} \mathrm{W}\right)$, and the Tree Nob Islands, which consisted of a cluster of 3 sampling locations: Site $1,54^{\circ} 12.587^{\prime} \mathrm{N}, 130^{\circ} 49.521^{\prime} \mathrm{W}$; Site 2, $54^{\circ} 13.042^{\prime} \mathrm{N}, 130^{\circ} 47.36^{\prime} \mathrm{W}$; and Site $3,54^{\circ} 15.676^{\prime} \mathrm{N}$, $130^{\circ} 48.609^{\prime} \mathrm{W}$ (Fig. 1). Specimens were collected alive during density surveys conducted by commercial geoduck harvesters in the summer of 2004 (Tree Nob Islands and Bartlett Beach) and 2003 (Brady's Beach) at depths ranging from 6 to $20 \mathrm{~m}$. Acetate peels were made from the hinge plate region of sectioned geoduck specimens by the Canada Department of 


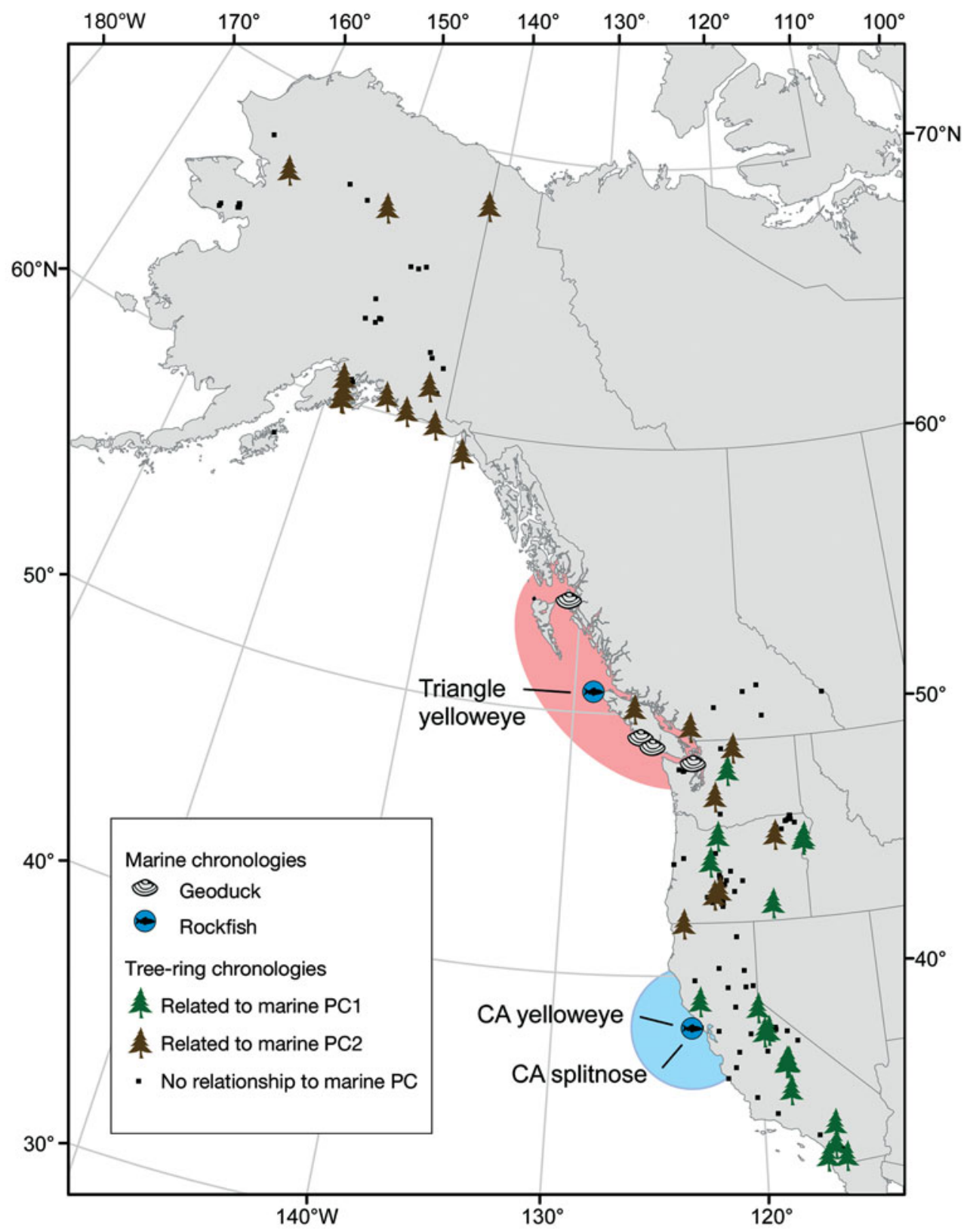

Fig. 1. Western North America and locations of all marine and tree-ring chronologies used in the present study. Tree-ring chronologies that significantly relate to the first and second principal components (PC1 and PC2, respectively) extracted from the marine chronologies are identified. Pink (blue) shading denotes the region where marine chronologies positively (negatively) relate to ocean temperature. Pacific rockfish (yelloweye and splitnose) chronologies included 2 in northern California (CA) and

1 near Triangle Island, British Columbia. The southernmost geoduck chronology was developed by Strom et al. (2004)

Fisheries and Oceans at the Pacific Biological Station, Nanaimo, British Columbia, following standard techniques (Black et al. 2008c). Also included in the analysis was an existing geoduck chronology from Puget Sound, Washington, which was generated using similar methods (Fig. 1) (Strom et al. 2004). For rockfish and geoduck, only the oldest individuals with the clearest growth increments were selected for chronology development (Black et al. 2005, 2008a, 2008c).
Cross-dating and chronology development. Samples were photographed with a Leica DC300 7.2 megapixel digital camera attached to a Leica MZ9 $9_{5}$ dissection scope and visually crossdated using the 'list year' technique (Yamaguchi 1991, Black et al. 2005, Black et al. 2008c). Once visual cross-dating was complete, growth increments were measured along the axis of growth (i.e. perpendicular to annuli) using the caliper function in the program ImagePro Plus v. 6.0 (Media 
Cybernetics). In rockfish, measurements followed the clearest possible axis on the dorsal half of the otolith, while in geoduck samples, measurements followed the axis of most rapid growth. Due to the rapidly changing geometry that occurred during early growth, the first 5 to $7 \mathrm{yr}$ of growth were excluded in all species.

Cross-dating was statistically verified using the International Tree-Ring Data Bank Program Library program COFECHA (Holmes 1983, Grissino-Mayer 2001). Next, measurement time series were detrended with negative exponential functions, which should remove age-related trends while preserving as much remaining long-term variability as possible. Within each species and site, all detrended series were averaged into a master chronology using a biweight robust mean to reduce the effects of outliers (Cook 1985). All aspects of chronology development were conducted using the International Tree-Ring Data Bank program ARSTAN (Cook 1985). The quality of the chronology was quantified using the expressed population signal (EPS) statistic, which is a measure of chronology error that determines how well a chronology, based on a finite number of samples, estimates the theoretical population chronology from which it has been drawn. Though there is no significant threshold for this statistic, an EPS value of 0.85 or greater is considered adequate by dendrochronologists for climate reconstruction, a level more than sufficient for the purposes of the present study (Wigley et al. 1984). Mean sensitivity, an index of high-frequency, year-to-year growth variability was also calculated (Fritts 1976).

Relationships to climate and tree-ring data. Prior analysis indicated that all Pacific geoduck chronologies correlated strongly and positively with sea surface temperatures, but that they occasionally experienced growth depressions accompanied by breakdowns in climate-growth relationships (B. A. Black. unpubl. data). These depressions typically lasted a decade or less and were not synchronous across sites. Therefore, geoduck chronologies were averaged to cancel out these anomalies, providing much stronger relationships with ocean variability. The composite geoduck chronology, splitnose rockfish chronology, and the 2 yelloweye rockfish chronologies were entered into principal components analysis.

Marine chronologies and their principal components were correlated with monthly values of the Multivariate El Niño Southern Oscillation Index (MEI) and the Pacific Decadal Oscillation (PDO). The MEI is the leading principal component of 6 marine and atmospheric variables in the tropical Pacific, while the PDO is the leading principal component of North Pacific sea surface temperatures poleward of $20^{\circ} \mathrm{N}$ (Mantua et al. 1997, Wolter \& Timlin 1998). MEI data (1950 to 1994) were obtained from the NOAA Earth Systems Research Laboratory (NOAA/ESRL 2008) while PDO data were obtained from the University of Washington Joint Institute for the Study of the Atmosphere and the Ocean (JISAO 2008). For those chronologies with significant $(p<0.05)$ firstorder autocorrelation, the number of degrees of freedom were adjusted according to the method of Pyper \& Peterman (1998). Principal components from the marine chronologies were also related to climate variables using forward stepwise multiple regression $(\alpha=$ $0.05)$ followed by bootstrapping. At each iteration $(n=1000)$ of the bootstrapping technique, a calibration dataset equal to the number of years shared by the principal component and the climate variables was randomly selected with replacement. Thus, some years in this shared time period were omitted while other years were selected multiple times. Those years not selected were used as an independent verification dataset. For the dependent and independent datasets, the mean and SD of model parameters, as well as $\mathrm{R}^{2}$, were calculated at each iteration. The reduction of error coefficient (RE), a measure of shared variance between the independent data and the values modeled from the calibration dataset, was also calculated at each iteration (Fritts 1976). The maximum theoretical value of the RE statistic is +1 , and any positive value indicates that the regression model has some degree of skill.

All available tree-ring datasets from Alaska, British Columbia, Washington, Oregon, and California were downloaded from the NOAA Paleoclimate International Tree Ring Data Bank (ITRDB) for comparison with principal components from the marine chronologies (NOAA 2007). However, only the 241 tree-ring datasets collected after 1990 (i.e. the last year in the chronology was at least as recent as 1990) were retained in order to maximize overlap with the marine principal components. For some datasets the ITRDB provided original ring-width measurements instead of a completed tree-ring chronology. In these 22 instances, a chronology was generated using negative exponential detrending using the program ARSTAN (Cook 1985). Each 'standard' tree-ring chronology was then related to the multiple marine chronology principal components using forward stepwise regression $(\alpha=$ 0.05 ), for a total of 241 regressions (i.e. 1 regression for every tree-ring chronology).

\section{RESULTS}

Each marine chronology contained strongly synchronous growth patterns and was annually resolved. Interseries correlation, the mean correlation between 
Table 1. Marine growth chronology properties. Mean sensitivity is an index of high-frequency variability in which higher values indicate stronger year-to-year variability. Interseries correlation represents the mean correlation between each detrended sample and the average of all others. EPS: Expressed population signal

\begin{tabular}{|c|c|c|c|c|c|c|}
\hline Species & Chronology & $\begin{array}{c}\text { No. measurement } \\
\text { time series }\end{array}$ & $\begin{array}{c}\text { Mean } \\
\text { sensitivity }\end{array}$ & $\begin{array}{l}\text { Interseries } \\
\text { correlation }\end{array}$ & $\begin{array}{c}\text { Mean series } \\
\text { length (yr) }\end{array}$ & $\begin{array}{l}\text { Chronology span } \\
\quad(\text { EPS > 0.85) }\end{array}$ \\
\hline Yelloweye rockfish & California & 27 & 0.20 & 0.54 & 25.7 & 1948-2001 \\
\hline Yelloweye rockfish & Triangle Island & 21 & 0.20 & 0.65 & 44.7 & $1954-2002$ \\
\hline Splitnose rockfish & California & 48 & 0.15 & 0.55 & 46.3 & 1948-1994 \\
\hline Pacific geoduck & Tree Nob Islands & 66 & 0.29 & 0.74 & 51.4 & $1888-2003$ \\
\hline Pacific geoduck & Bartlett Beach & 40 & 0.24 & 0.71 & 52.6 & $1937-2003$ \\
\hline Pacific geoduck & Brady's Beach & 30 & 0.22 & 0.71 & 50.3 & $1934-2001$ \\
\hline Pacific geoduck & Strom et al. (2004) & 74 & 0.25 & 0.76 & 71.6 & $1877-1999$ \\
\hline
\end{tabular}

each detrended sample and the average of all others, ranged from 0.540 to 0.756 , and was slightly higher for Pacific geoduck than Pacific rockfish (Table 1). Geoduck chronologies were also longer and exhibited somewhat stronger variations in ring width, as indicated by relatively high mean sensitivity values (Table 1). The California yelloweye $(\mathrm{r}=-0.512)$ chronology and all geoduck chronologies, including the composite $(\mathrm{r}=$ $0.56)$, contained significant autocorrelation ( $p<0.05)$. With respect to interrelationships among chronologies, correlation analysis revealed positive relationships within, yet inverse relationships between, the northern chronologies (geoduck and Triangle yelloweye) and the 2 California rockfish chronologies (Table 2). The northern and southern chronologies were more strongly distinguished from one another in their correlations with the MEI, which positively correlated with the northern 2 chronologies and negatively correlated with the 2 southern chronologies (Fig. 2A); this pattern was most pronounced from the prior summer through current spring. Late in the growing season, correlations with the MEI declined for most chronologies, except for the California yelloweye chronology in which correlations became strongly positive in the current summer and fall (Fig. 2A). Correlations with the PDO tracked those of the MEI, but were generally weaker, especially for rockfish. A notable exception was the relationship between geoduck and spring PDO (Fig. 2B).

In the principal components analysis of the chronologies, the first principal component (PC1) explained $52.7 \%$ of the variance in the dataset, while the second component (PC2) explained an additional 23.2\% (Fig. 3). Neither contained significant autocorrelation. PC1 separated the 2 northern and 2 southern chronologies, while PC2 separated the splitnose rockfish chronology and the Triangle yelloweye chronology from the California yelloweye chronology and the geoduck chronology (Table 2). The 3rd and 4th components captured only an additional 15 and $10 \%$ of the variance, respectively, and were excluded from further analysis. When related to monthly averages of the MEI and PDO, PC1 correlated strongly and positively from the prior summer to the current spring (Fig. 4). For PC2, significant correlations occurred later in the year, spanning the current spring through the current fall (Fig. 4). In a linear regression, $45.7 \%$ of the variance in PC1 was explained by the average MEI from the prior summer through the current spring, while $46.6 \%$ of the variance in PC2 was explained by the average MEI for the current summer and fall. For PC1, using only the average of February and March MEI increased the variance explained to $49.8 \%$ (Fig. 3). In a bootstrapping analysis of these climate-growth regressions, slopes ( $\mathrm{p}$ $=0.61$ for $\mathrm{PC} 1 ; \mathrm{p}=0.13$ for $\mathrm{PC} 2)$ and intercepts $(\mathrm{p}=0.39$ for $\mathrm{PC} 1$ and $\mathrm{p}=0.88$ for $\mathrm{PC} 2$ ) calculated for the independent and dependent datasets did not significantly differ from one another. RE values were positive at 0.55 $\pm 0.009(95 \% \mathrm{CI})$ and $0.53 \pm 0.009$ for PC1 and PC2, respectively, indicating good agreement between independent and modeled values. No PDO variables related as strongly as MEI variables, nor did they significantly $(\alpha=0.05)$ improve variance explained in PC1 or PC2 when added as a second variable to the original MEI regressions.

In regression analyses, 45 out of the 241 tree-ring chronologies significantly related to a marine principal

Table 2. Correlation coefficients (r) among marine chronologies from 1954 to 1990. Significant $(p<0.05)$ correlations are in bold. First and second principal components (PC1 and PC2, respectively) scores for each chronology are given. Triangle: Triangle Island

\begin{tabular}{|lcccrr|}
\hline & $\begin{array}{c}\text { Triangle } \\
\text { yelloweye }\end{array}$ & $\begin{array}{c}\text { California } \\
\text { yelloweye }\end{array}$ & $\begin{array}{c}\text { California } \\
\text { splitnose }\end{array}$ & $\begin{array}{c}\text { PC1 } \\
\text { scores }\end{array}$ & $\begin{array}{r}\text { PC2 } \\
\text { scores }\end{array}$ \\
\hline Pacific geoduck & $\mathbf{0 . 3 9}$ & -0.17 & $\mathbf{- 0 . 3 7}$ & 0.44 & 0.54 \\
Triangle yelloweye & & $\mathbf{- 0 . 5 8}$ & $\mathbf{- 0 . 4 7}$ & 0.60 & -0.21 \\
California yelloweye & & & 0.19 & -0.46 & 0.69 \\
California splitnose & & & -0.48 & -0.43 \\
\hline
\end{tabular}




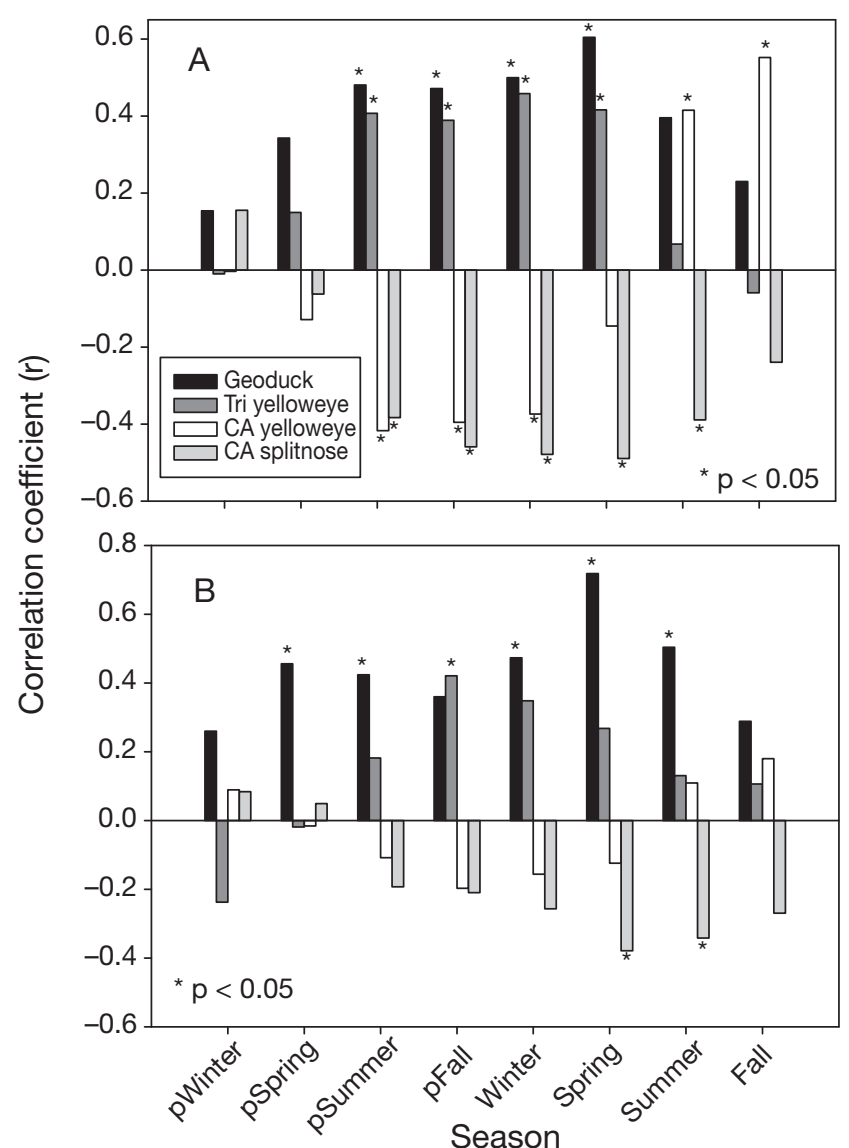

Fig. 2. Correlations between each marine chronology (geoduck bivalves and yelloweye and splitnose rockfishes) and seasonally averaged values of the (A) Multivariate ENSO Index (MEI) and (B) the Pacific Decadal Oscillation (PDO) over the current and prior (p) year. CA: California; tri: Triangle Island

component (Fig. 1). Southern tree-ring chronologies tended to relate to PC1, while those in the north related to PC2 (Fig. 1). Every significant relationship was positive, and $\mathrm{R}^{2}$ values ranged from 0.108 to 0.375 (mean $=0.163)$. In only 2 tree-ring chronologies, one in Washington and another in California, were both marine principal components significant in the regression model. Tree-ring chronologies that significantly related to a marine principal component were from coniferous genera (Pinus, Tsuga, Abies, Pseudotsuga, Juniperus, and Larix) with the exception of one oak Quercus douglasii chronology. These chronologies occurred at high elevation sites in the south (approximately $2000 \mathrm{~m}$ at $35^{\circ} \mathrm{N}$ ) and lower elevation sites (approximately $500 \mathrm{~m}$ at $60^{\circ} \mathrm{N}$ ) in the north. A regression between elevation and latitude was highly significant $\left(\mathrm{R}^{2}=0.600, \mathrm{p}<0.0001\right)$, increasing to $0.818(\mathrm{p}<$ 0.0001) when the oak chronology and a coastal Torrey pine Pinus torreyana chronology were dropped. Both of these chronologies occurred at unusually low-

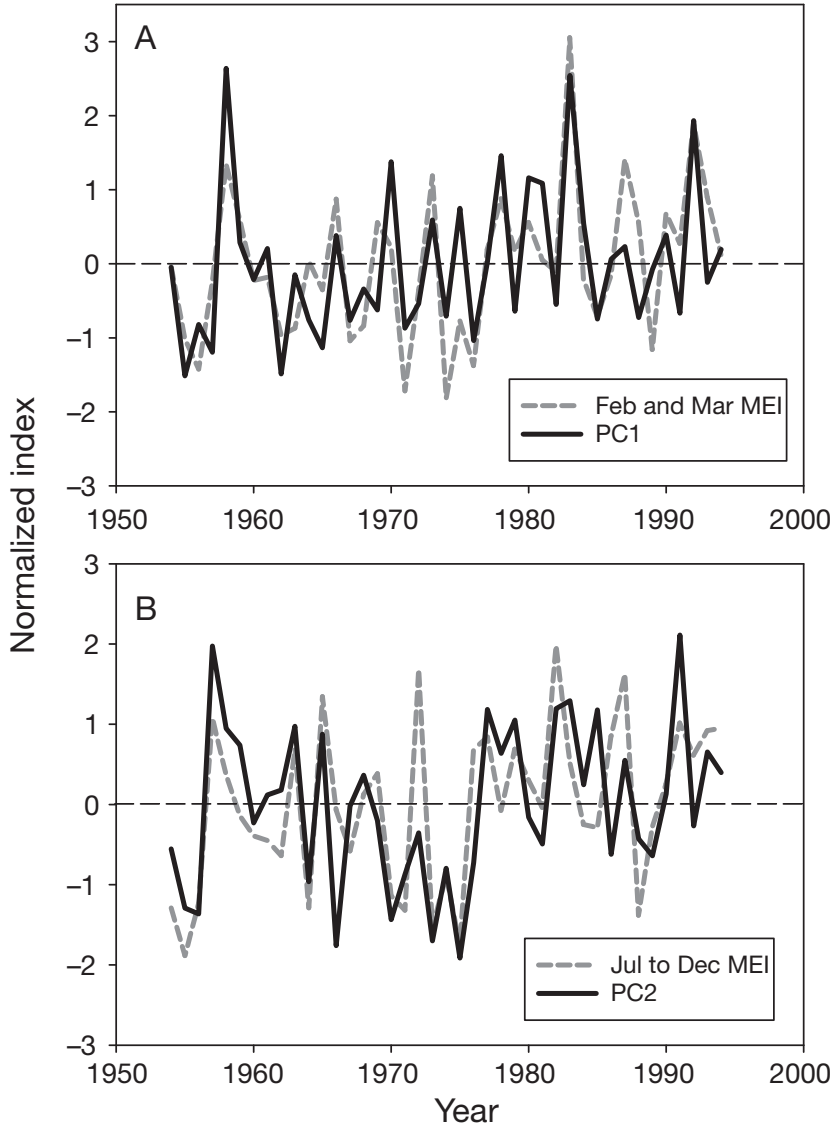

Fig. 3. (A) Principal component (PC) 1 extracted from marine growth-increment chronologies, and mean February to March Multivariate ENSO Index (MEI) values. (B) PC2 extracted from marine growth-increment chronologies, and mean July to December MEI values. All time series are normalized to a mean of zero and SD of 1

elevation sites given their latitudes in comparison to other chronologies that were significantly related to a marine principal component.

\section{DISCUSSION}

Marine chronologies used in the present study were annually resolved and of a quality comparable to that of tree-ring chronologies. Each strongly related to measures of environmental variability and in a manner consistent with species biology and broad-scale patterns of ocean circulation. In particular, the inverse growth regime between northern and southern chronologies closely mirrored the physical and biological oceanography of the coastal northeast Pacific, which can be divided into 3 domains: (1) a transition domain, where the eastward-flowing Subarctic Current bifurcates as it meets the North American continent, generally between $45^{\circ}$ and $50^{\circ} \mathrm{N}$; (2) a coastal 


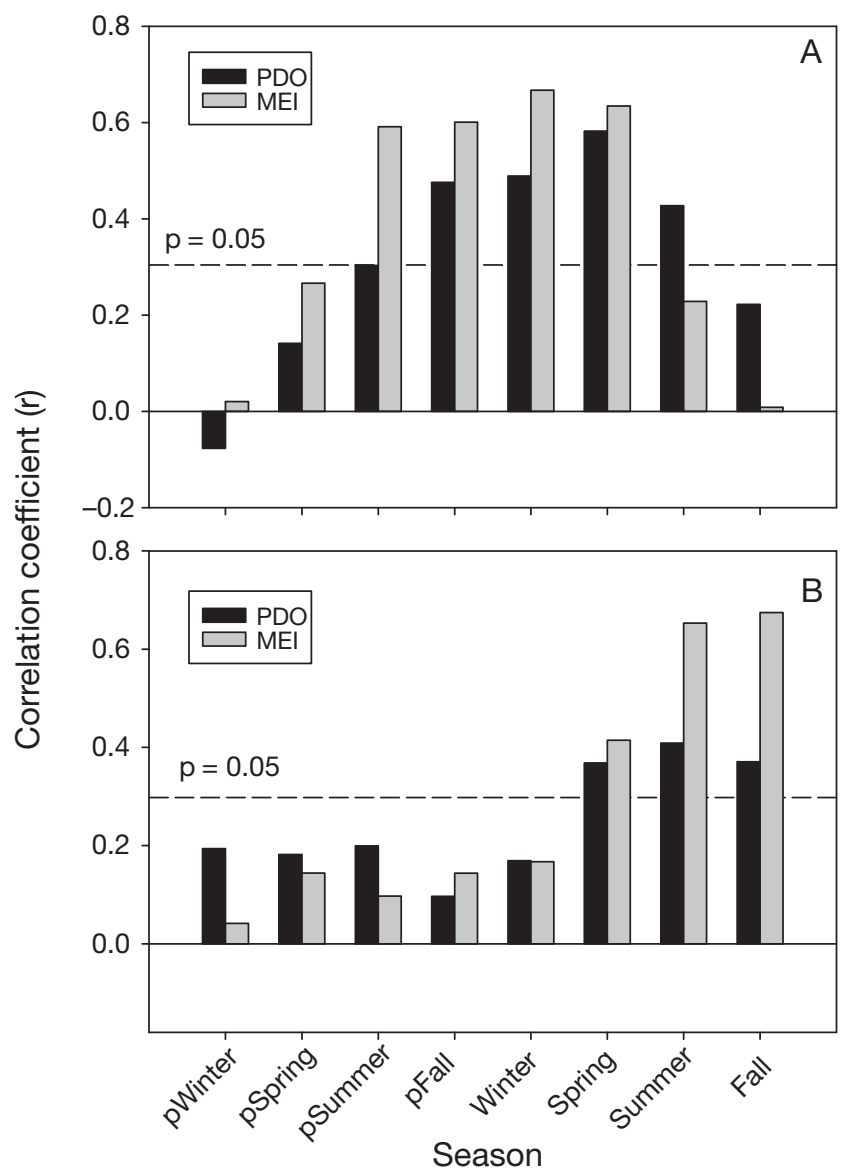

Fig. 4. Correlations between climate and (A) principal component (PC) 1 and (B) PC2 extracted from marine growth chronologies. Climate variables are seasonally averaged values of the Multivariate ENSO Index (MEI) and Pacific Decadal Oscillation (PDO) over the current and prior $(\mathrm{p})$ year

downwelling domain to the north that follows the poleward-flowing Alaska Current; and (3) a coastal upwelling domain to the south that follows the equatorial-flowing California Current (Ware \& McFarlane 1989). One of the most pronounced differences among these regions is that productivity levels between the northern downwelling domain and the southern upwelling domain oppose one another. Primary and secondary productivity are positively associated with indicators of ocean temperature in the downwelling domain, (McFarlane \& Beamish 1992, Brodeur et al. 1996) but negatively associated with these indicators farther south in the upwelling domain (Roemmich \& Mcgowan 1995, Hooff \& Peterson 2006). Therefore, during warm years in the northeast Pacific, as would occur during El Niño events, lower trophic productivity is high in the north and low in the south, with the reverse during cool years. Given that positive values of the MEI and PDO are associated with warm ocean conditions throughout the study area (and vice versa for negative values), climate-growth relationships for each chronology in the present study were consistent with productivity patterns. Indeed, this inverse growth regime was the dominant signal in the dataset, as captured by PC1 from the marine chronologies. High values indicate robust growth in the north and poor growth in the south, explaining the positive correlations with the PDO and MEI.

These interrelationships among chronologies and climate are also consistent with other fisheries studies throughout the region, including those that involve other Pacific rockfish. For example, a yelloweye rockfish chronology developed at Bowie Seamount $\left(53^{\circ} 20^{\prime} \mathrm{N}, 135^{\circ} 40^{\prime} \mathrm{W}\right)$ in the downwelling domain, but not included in the present study due to its relatively short length (1961 to 2003), exhibited strongly positive relationships with indicators of warm ocean conditions (Black et al. 2008a). To the south in the upwelling domain, however, warm events such as the 1983 El Niño significantly reduced the growth-increment width of widow rockfish Sebastes entomelas and yellowtail rockfish Sebastes flavidus, as well as levels of visceral fat in yellowtail rockfish (Lenarz \& Echeverria 1986, Woodbury 1999). Also, salmon (Oncorhynchus spp.) catch was relatively high for Washington, Oregon, and California stocks but low for Alaska stocks during cool PDO phases, and vice versa during warm PDO phases (Hare \& Francis 1995, Hare et al. 1999), similar to the climate-growth relationships identified in the present study. At least for rockfish, in which northern as well as southern chronologies could be developed, the results of the present study provide additional support for an inverse growth regime at higher trophic levels, and suggest that this regime is indirectly driven by climate via its effects on lower trophic productivity.

With respect to Pacific geoduck, chronologies to date have been developed only for the northern portion of the study region, all of which strongly and positively relate to sea surface temperatures (Noakes \& Campbell 1992, Strom et al. 2004). Due to low population numbers, no chronologies have been developed farther south in the California Current to help identify whether growth-increment width is a function of the physical environment or lower-trophic productivity. In the laboratory, however, experiments in other marine bivalve species indicate that water temperature maintains positive controls on metabolism and shell growth rate, even when food is withheld and specimens lose tissue weight (Cerrato 2000). As for Pacific geoduck, experiments with 1 yr-old individuals suggest that both food and temperature may be limiting, though very high shell growth rates occurred in Puget Sound adults during the 1990s when temperatures were high and food abundance was presumed to be low (Strom 2003, Strom et al. 2004). Overall, these findings indicate a 
more direct relationship between climate and growthincrement width for Pacific geoduck than Pacific rockfish. Yet despite such differences, as well as those in life history and habitat, Pacific geoduck and rockfish chronologies exhibit remarkably similar growth patterns, suggesting that climate can synchronize growth across broad spatial scales, among diverse species, through direct (i.e. temperature driving growth through metabolism) and indirect (i.e. climate driving growth through effects on food supply) pathways in the northeast Pacific.

In contrast to PC1, the PC2 did not separate chronologies along any apparent species-specific or spatial trends. Instead, PC2 captured a unique mode of growth associated with climate variability during the summer and fall. More specifically, a ranking of all chronologies according to their correlations with summer and fall MEI matched their rankings along PC2, ranging from negative (splitnose rockfish) to weak (Triangle yelloweye rockfish) to positive (California yelloweye rockfish). In comparison to climate-growth relationships in the winter and spring, perhaps the greatest difference is the switch from negative to positive correlations between the MEI and the California yelloweye rockfish. Farther north, a similar reversal in climate-growth relationships was also observed for a yelloweye rockfish chronology at Bowie Seamount (Black et al. 2008a), a phenomenon that could be an artifact of reproductive output or an indicator that warm ocean conditions in some way extended the growing season. Ultimately, however, PC2 highlights the fact that climate-growth relationships are not constant throughout the year. Though the inverse growth regime captured by $\mathrm{PC} 1$ is by far the most dominant signal in the data, this mode deteriorates by the summer and is replaced by a new and unique synchronous growth pattern that persists for the remaining 2 or $3 \mathrm{mo}$. What is particularly remarkable about both principal components is the degree to which they relate to environmental variability. Climate-growth relationships are sufficiently strong that current or forecast MEI could provide at least some power to predict the state of these principal components. For example, positive MEI values in February and March suggest that growth will be relatively strong in the north and relatively poor in the south (and vice versa during years with negative MEI values). Also, forecasts from climate models could be used to evaluate the effects of climate change on growth over the coming decades.

On land, approximately $18 \%$ of tree-ring chronologies significantly relate to a marine principal component, nearly 4 times as many as would be expected by chance alone. Furthermore, significant chronologies are not randomly located across the landscape, but occur along a specific latitudinal and elevational tran- sect, related to PC1 in the south and PC2 in the north, and always yielded a positive correlation. These relationships are consistent with couplings between the ocean and the atmosphere and their impacts on tree growth. For example, in southeast Alaska, tree-ring chronologies are positively associated with spring and summer land temperatures, which are positively associated with sea surface temperatures (Wiles et al. 1998, D'Arrigo et al. 1999, Gedalof \& Smith 2001). In the Cascade Mountains and northern California, snowpack becomes an additional limiting variable, the depth and duration of which negatively correlate with winter and spring ocean temperatures (Gedalof \& Smith 2001, Peterson et al. 2002). Farther south, precipitation is positively associated with warm waters, and tree growth is most negatively impacted by drought, as would occur during La Niña events or negative phases of the PDO (Biondi et al. 1999, Biondi et al. 2001). For these various reasons, tree-ring chronologies positively relate to the PDO and MEI, as do the 2 principal components derived from the marine chronologies. Also, trees from more northerly sites should better relate to $\mathrm{PC} 2$ considering that, at these latitudes, climate is most limiting to growth in the spring and summer months (Wiles et al. 1998, Gedalof \& Smith 2001). Winter environmental variability, particularly precipitation, becomes an increasingly important influence on tree growth farther south (Biondi et al. 2001), better matching the seasonality represented by PC1. The interconnectedness of these diverse datasets corroborates accuracy and demonstrates the potential for chronologies in the terrestrial system to serve as proxies for those in the ocean, as has been done for various aspects of the physical environment such as SST or the PDO (D'Arrigo et al. 1999).

Overall, marine chronologies and their principal components provide continuous, annually-resolved indices of growth for an environment in which longterm records are relatively scarce. They also illustrate the degree to which climate synchronizes growth across diverse taxa and broad spatial scales, acting through a manner consistent with species' ecological attributes and the oceanography of the region. Via couplings between the ocean and atmosphere, tree growth is synchronized with growth patterns in the marine environment, such that organisms living at $300 \mathrm{~m}$ depth relate to those in high-elevation mountain forests. These interrelationships provide a means to corroborate, strengthen, and possibly extend growth chronologies in all environments. For example, treering chronologies may one day be used to extend marine chronologies back in time, providing context for interpreting modern growth trends and generating baseline data on historical ranges of variability. Finally, growth chronologies reveal that climate-growth rela- 
tionships can be highly seasonal with multiple modes of growth occurring over the course of a year. Targeting the seasonality of climate-growth relationships not only improves understanding of the effects of environmental variability, but may also help with forecasting biological responses in the face of future climate variability and change. Considering the wide range of organisms that form annual growth increments, chronology development could be greatly expanded to provide growth indices for the marine environment, quantify long-term trends, establish climate-growth relationships, and identify interrelationships among diverse species and ecosystems.

Acknowledgements. The author thanks G. Boehlert and M. Yoklavich for their ongoing support and collaboration. Also, thanks to R. Kormanyos, M. Stuckey, D. Gillespie, C. Hand, S. MacLellan, and the members of the 16th annual North American Dendroecology Fieldweek for their help in developing Pacific geoduck chronologies. Many thanks to D. Pearson and L. Yamanaka for supplying yelloweye rockfish otoliths, and also to the contributors of the International Tree Ring Data Bank. An earlier draft of this manuscript was reviewed by W. T. Peterson, J. Dunham, and J. Colbert. This research was funded by the Department of Fisheries and Oceans, Canada, and the NOAA Fisheries and the Environment Program through grant no. NA06NMF4550286 to the Oregon State University Cooperative Institute for Marine Resources Studies.

\section{LITERATURE CITED}

Biondi F, Cayan DR, Berger WH (1999) Decadal-scale changes in southern California tree-ring records. In: Karl TR (ed) Proceedings of the 10th Symposium on Global Climate Change Studies. American Meteorological Society, Boston, MA, p 303-306

Biondi F, Gershunov A, Cayan DR (2001) North Pacific decadal climate variability since 1661. J Clim 14:5-10

Black BA, Boehlert GW, Yoklavich MM (2005) Using tree-ring cross-dating techniques to validate annual growth increments in long-lived fishes. Can J Fish Aquat Sci 62: 2277-2284

Black BA, Boehlert GW, Yoklavich MM (2008a) Establishing climate-growth relationships for yelloweye rockfish (Sebastes ruberrimus) in the northeast Pacific using a dendrochronological approach. Fish Oceanogr 17:368-379

Black BA, Colbert JJ, Pederson N (2008b) Relationships between radial growth rates and lifespan within North American tree species. Ecoscience 15:349-357

Black BA, Gillespie D, MacLellan SE, Hand CM (2008c) Establishing highly accurate production-age data using the tree-ring technique of cross-dating: a case study for Pacific geoduck (Panopea abrupta). Can J Fish Aquat Sci 65:2572-2578

Boehlert GW, Yoklavich MM, Chelton DB (1989) Time-series of growth in the genus Sebastes from the northeast Pacific-Ocean. Fish Bull 87:791-806

Brodeur RD, Frost BW, Hare SR, Francis RC, Ingraham WJ Jr (1996) Interannual variations in zooplankton biomass in the Gulf of Alaska, and covariation with California Current zooplankton biomass. Calif Coop Ocean Fish Invest Data Rep 37:80-99
Campana SE (2001) Accuracy, precision and quality control in age determination, including a review of the use and abuse of age validation methods. J Fish Biol 59:197-242

Cerrato RM (2000) What fish biologists should know about bivalve shells. Fish Res 46:39-49

Cissel JH, Swanson FJ, Weisberg PJ (1999) Landscape management using historical fire regimes: Blue River, Oregon. Ecol Appl 9:1217-1231

Cook ER (1985) A time-series analysis approach to tree-ring standardization. PhD Thesis, University of Arizona

Cook ER, Meko DM, Stahle DW, Cleaveland MK (1999) Drought reconstructions for the continental United States. J Clim 12:1145-1162

Cook ER, Glitzenstein JS, Krusic PJ, Harcombe PA (2001) Identifying functional groups of trees in west Gulf Coast forests (USA): a tree-ring approach. Ecol Appl 11:883-903

D'Arrigo R, Wiles G, Jacoby G, Villalba R (1999) North Pacific sea surface temperatures: past variations inferred from tree rings. Geophys Res Lett 26:2757-2760

> Esper J, Cook ER, Schweingruber FH (2002) Low-frequency signals in long tree-ring chronologies for reconstructing past temperature variability. Science 295:2250-2253

> Evans MN, Kaplan A, Cane MA (2002) Pacific sea surface temperature field reconstruction from coral $\delta^{18} \mathrm{O}$ data using reduced space objective analysis. Paleoceanography 17, 1007, doi: 10.1029/2000PA000590

Fritts HC (1976) Tree rings and climate. Academic Press, New York

> Gedalof Z, Smith DJ (2001) Dendroclimatic response of mountain hemlock (Tsuga mertensiana) in Pacific North America. Can J For Res 31:322-332

> Goodkin NF, Hughen KA, Cohen AL, Smith SR (2005) Record of Little Ice Age sea surface temperatures at Bermuda using a growth-dependent calibration of coral Sr/Ca. Paleoceanography 20, PA4016, doi: 10.1029/2005PA001140

Grissino-Mayer HD (2001) Evaluating cross-dating accuracy: a manual and tutorial for the computer program COFECHA. Tree-Ring Res 57:205-221

Hare SR, Francis RC (1995) Climate change and salmon production in the northeast Pacific Ocean. In: Beamish RJ (ed) Climate change and northern fish populations, Vol 121. Department of Fisheries and Oceans, Ottawa, p 245-260

Hare SR, Mantua NJ, Francis RC (1999) Inverse production regimes: Alaska and West Coast Pacific salmon. Fisheries 24:6-14

> Helama S, Schone BR, Black BA, Dunca E (2006) Constructing long-term proxy series for aquatic environments with absolute dating control using a sclerochronological approach: introduction and advanced applications. Mar Freshw Res 57:591-599

> Hendy EJ, Gagan MK, Lough JM (2003) Chronological control of coral records using luminescent lines and evidence for non-stationary ENSO teleconnections in northeast Australia. Holocene 13:187-199

Holmes RL (1983) Computer-assisted quality control in treering dating and measurement. Tree-Ring Bull 43:69-78

Hooff RC, Peterson WT (2006) Copepod biodiversity as an indicator of changes in ocean and climate conditions of the northern California current ecosystem. Limnol Oceanogr 51:2607-2620

JISAO (2008) The Pacific Decadal Oscillation. Available at jisao.washington.edu/pdo/

Lenarz WH, Echeverria TW (1986) Comparison of visceral fat and gonadal fat volumes of yellowtail rockfish, Sebastes flavidus, during a normal year and a year of El Niño conditions. Fish Bull 84:743-745 
Love MS, Yoklavich MM, Thorsteinson L (2002) The rockfishes of the northeast Pacific. University of California Press, Los Angeles, CA

Mann ME, Bradley RS, Hughes MK (1998) Global-scale temperature patterns and climate forcing over the past six centuries. Nature 392:779-787

Mantua NJ, Hare SR, Zhang Y, Wallace JM, Francis RC (1997) A Pacific interdecadal climate oscillation with impacts on salmon production. Bull Am Meteorol Soc 78: 1069-1079

McFarlane GA, Beamish RJ (1992) Climatic influence linking copepod production with strong year-classes in sablefish, Anoplopoma fimbria. Can J Fish Aquat Sci 49:743-753

NOAA (2007) International Tree-Ring Data Bank. Available at www.ncdc.noaa.gov/paleo/treering.html

NOAA/ESRL (2008) Multivariate ENSO Index (MEI). Available at www.cdc.noaa.gov/people/klaus.wolter/MEI/

> Noakes DJ, Campbell A (1992) Use of geoduck clams to indicate changes in the marine environment of Ladysmith Harbor, British Columbia. Environmetrics 3:81-97

> Orwig DA, Abrams MD (1994) Contrasting radial growth and canopy recruitment patterns in Liriodendron tulipifera and Nyssa sylvatica: gap-obligate versus gap-facultative tree species. Can J For Res 24:2141-2149

Peterson DW, Peterson DL, Ettl GJ (2002) Growth responses of subalpine fir to climatic variability in the Pacific Northwest. Can J For Res 32:1503-1517

Pyper BJ, Peterman RM (1998) Comparison of methods to account for autocorrelation in correlation analyses of fish data. Can J Fish Aquat Sci 55:2127-2140

Roemmich D, Mcgowan J (1995) Climatic warming and the decline of zooplankton in the California Current. Science 267:1324-1326

Schone BR, Castro ADF, Fiebig J, Houk SD, Oschmann W, Kroncke I (2004) Sea surface water temperatures over the period 1884-1983 reconstructed from oxygen isotope ratios of a bivalve mollusk shell (Arctica islandica, southern North Sea). Palaeogeogr Palaeoclimatol Palaeoecol 212: 215-232

Editorial responsibility: Jon Hare, Narragansett, Rhode Island, USA
Speer JH, Swetnam TW, Wickman BE, Youngblood A (2001) Changes in pandora moth outbreak dynamics during the past 622 years. Ecology 82:679-697

Strom A (2003) Climate and fisheries in the Pacific northwest: historical perspectives from geoducks and early explorers. MS Thesis, University of Washington, Seattle, WA

Strom A, Francis RC, Mantua NJ, Miles EL, Peterson DL (2004) North Pacific climate recorded in growth rings of geoduck clams: a new tool for paleoenvironmental reconstruction. Geophys Res Lett 31, L06206, doi:10.1029/ 2004GL019440

Swetnam TW, Betancourt JL (1990) Fire-Southern Oscillation relations in the southwestern United States. Science 249:1017-1020

Swetnam TW, Allen CD, Betancourt JL (1999) Applied historical ecology: using the past to manage for the future. Ecol Appl 9:1189-1206

Taylor AH, Skinner CN (2003) Spatial patterns and controls on historical fire regimes and forest structure in the Klamath Mountains. Ecol Appl 13:704-719

Ware DM, McFarlane GA (1989) Fisheries production domains in the northeast Pacific Ocean. In: Beamish RJ, McFarlane GA (eds) Effects of ocean variability on recruitment and evaluation of parameters used in stock assessment models, Vol 108. Department of Fisheries and Oceans, Ottawa, p 359-379

Wigley TML, Briffa KR, Jones PD (1984) On the average value of correlated time-series, with applications in dendroclimatology and hydrometeorology. J Clim Appl Meteorol 23:201-213

- Wiles GC, D'Arrigo RD, Jacoby GC (1998) Gulf of Alaska atmosphere-ocean variability over recent centuries inferred from coastal tree-ring records. Clim Change 38: 289-306

Wolter K, Timlin MS (1998) Measuring the strength of ENSO events: How does 1997/98 rank? Weather 53:315-324

Woodbury D (1999) Reduction of growth in otoliths of widow and yellowtail rockfish (Sebastes entomelas and S. flavidus) during the 1983 El Niño. Fish Bull 97:680-689

> Yamaguchi DK (1991) A simple method for cross-dating increment cores from living trees. Can J For Res 21:414-416

Submitted: August 11, 2008; Accepted: November 24, 2008 Proofs received from author(s): March 5, 2009 